\title{
310 Ciclooxigenase-2 nos carcinomas ductais de mama invasivos com componente ductal in situ e no epitélio adjacente
}

Vilmar Marques de Oliveira Maria Marta Martins

Adrienne Pratti Lucarelu

Giuliana Cássia Morrone Taromaru

JOSÉ FRANCISCO RINALDI

Maria Antonieta Longo Galvão Silva

SEBAstião PIATO

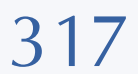

Hélo SEBAstião AmânCIO de CAMARGO JúNIOR Marcia Martos Amâncio de Camargo Sandra Regina Campos Teixeira Maurício de Souza ArRuda
Cyclooxygenase-2 in invasive ductal carcinoma with ductal component in situ and in adjacent epitbelium

\section{Artigo de Revisão}

\section{Tratamento atual dos miomas}

Helena von Eye Corleta

Eunice BeAtriz Martin Chaves

Miriam Sigrun Krause

EDISON CAPP
Treatment of leiomyomas

\section{Análise imuno-histoquímica do fibroadenoma mamário humano} por meio do antígeno de proliferação celular ki-67 durante as fases folicular e lútea do ciclo menstrual

Immunobistochemical analysis of buman mammary fibroadenoma by cell proliferation antigen ki-67 during the follicular and luteal phases of menstrual cycle

\section{Fatores de angiogênese na pré-eclâmpsia e a correlação com os} níveis da pressão arterial média

Angiogenic factor in preeclampsia and the correlation with mean arterial pressure

\section{Errata:}

Na edição anterior, o último parágrafo do artigo original "Correlação entre os níveis de proteína C reativa ultrasensível e as características clínicas e laboratoriais em mulheres com síndrome do ovário policístico" (página 241) saiu incompleto . O correto seria:

"Por fim, considerações devem ser feitas a respeito da aplicabilidade prática dos nossos achados. Entendemos que os nossos achados contribuem para a compreensão da SOP como uma doença de manifestações metabólicas precoces. $\mathrm{O}$ dano endotelial parece se apresentar de forma subclínica, mesmo em idade jovem. Portanto, um melhor entendimento destes aspectos acrescenta e reforça o embasamento científico que tem norteado a abordagem diagnóstica e terapêutica da mulher com SOP, vislumbrando uma redução dos riscos à saúde a curto, médio e longo prazo." 